\title{
Rates of Mass Transfer Controlled Electrochemical and Catalytic Reactions Conducted in a Fixed Bed Reactor Built of Lessing Rings
}

\author{
A.S. Fathalla, N.K. Amin, E-S.Z. El-Ashtoukhy ${ }^{*}$ and G.H. Sedahmed \\ Chemical Engineering Department, Faculty of Engineering, Alexandria University, Alexandria, Egypt \\ "E-mail: elsayed_elashtoukhy@ @otmail.com
}

doi: $10.20964 / 2016.06 .34$

Received: 22 February 2016 / Accepted: 5 April 2016 / Published: 4 May 2016

The mass transfer behaviour of a fixed bed of Lessing rings was studied using a technique which involves the diffusion controlled dissolution of copper in acidified dichromate. Variables studied were ring diameter, solution velocity and physical properties of the solution. The mass transfer coefficient was found to increase with increasing solution velocity and decreasing the ring diameter. The mass transfer data were correlated by the following dimensionless equation

$$
\mathrm{Sh}=1.076 \mathrm{Sc}^{0.33} \operatorname{Re}^{0.625}
$$

The above equation was found to predict mass transfer coefficients higher than those obtained by the electrochemical technique under the same conditions because of the non-uniform current distribution inside and outside the rings. Also, the present study has revealed that Lessing rings produce higher rates of mass transfer than Raschig rings under the same conditions. Implications of the above equation for the design and operation of catalytic and heterogeneous reactors used to conduct diffusion controlled liquid-solid reactions were highlighted.

Keywords: mass transfer; fixed bed electrochemical reactor; catalytic reactor; lessing rings; diffusion controlled reactions.

\section{$\underline{\text { FULL TEXT }}$}

(C) 2016 The Authors. Published by ESG (www.electrochemsci.org). This article is an open access article distributed under the terms and conditions of the Creative Commons Attribution license (http://creativecommons.org/licenses/by/4.0/). 